\title{
Framingham risk score for estimation of 10-years of cardiovascular diseases risk in patients with metabolic syndrome
}

\author{
Leila Jahangiry ${ }^{1}$, Mahdieh Abbasalizad Farhangi ${ }^{2^{*}}$ and Fatemeh Rezaei ${ }^{3}$
}

\begin{abstract}
Background: There are a few studies evaluating the predictive value of Framingham risk score (FRS) for cardiovascular disease (CVD) risk assessment in patients with metabolic syndrome in Iran. Because of the emerging high prevalence of CVD among Iranian population, it is important to predict its risk among populations with potential predictive tools. Therefore, the aim of the current study is to evaluate the FRS and its determinants in patients with metabolic syndrome.
\end{abstract}

Methods: In the current cross-sectional study, 160 patients with metabolic syndrome diagnosed according to the National Cholesterol Education Adult Treatment Panel (ATP) III criteria were enrolled. The FRS was calculated using a computer program by a previously suggested algorithm.

Results: Totally, 77.5, 16.3, and 6.3\% of patients with metabolic syndrome were at low, intermediate, and high risk of CVD according to FRS categorization. The highest prevalence of all of metabolic syndrome components were in low CVD risk according to the FRS grouping $(P<0.05)$, while the lowest prevalence of these components was in high CVD risk group $(P<0.05)$. According to multiple logistic regression analysis, high systolic blood pressure (SBP) and fasting serum glucose (FSG) were potent determinants of intermediate and high risk CVD risk of FRS scoring compared with low risk group $(P<0.05)$.

Conclusion: In the current study, significant associations between components of metabolic syndrome and different FRS categorization among patients with metabolic syndrome were identified. High SBP and FSG were associated with meaningfully increased risk of CVD compared with other parameters.

Trial registrations: The study is not a trial; the registration number is not applicable.

Keywords: Framingham risk score, Metabolic syndrome, Cardiovascular disease

\section{Background}

Metabolic syndrome defined as a cluster of metabolic risk factors including hypertension, obesity, hyperglycemia, and central obesity [1] is one of the most common health problems throughout the world. The disease has a strong association with the risk of cardiovascular events. It has been estimated that men with metabolic syndrome have 2-3 times greater probability for cardiovascular disease (CVD) than those without metabolic syndrome [2-4]. Overall, metabolic syndrome is associated with a twofold

\footnotetext{
* Correspondence: abbasalizad_m@yahoo.com

${ }^{2}$ Drug Applied Research Center, Department of Community Nutrition, Faculty of Nutrition, Tabriz University of Medical Sciences, Tabriz, Iran

Full list of author information is available at the end of the article
}

increase in the risk of CVD, CVD mortality, and stroke, and a 1.5-fold increase in risk of all-cause mortality [5-7]. In fact, coronary artery disease (CAD) is among the main causes of death in developed countries, while it has a growing epidemic in developing countries $[8,9]$. The Framingham risk score (FRS) is a simplified and common tool for the assessment of risk level of CAD over 10 years [10]. The FRS considers six coronary risk factors, including age, gender, total cholesterol (TC), high density lipoprotein cholesterol (HDL), smoking habits, and systolic blood pressure [11]. FRS is the most applicable method for predicting the person's chance of developing cardiovascular disease (CVD) in long term [12]. Because this risk score gives an indication of the likely benefits of 
prevention, it can be useful for both the patients and clinicians deciding whether lifestyle modification and preventive medical treatment and for patients education by identifying men and women at increased risk for future cardiovascular events [13]. Since metabolic syndrome is a complete cluster of metabolic risk factors of cardiovascular events including insulin resistance, central obesity, diabetes mellitus, and hyperlipidemia [14], it is necessary to predict the risk of cardiovascular disease in these patients. Moreover, limited data are available evaluating the predictive value of FRS in detecting the risk of CVD in patients with metabolic syndrome, and because of difference in the nature of CVD risk factors in different populations, its replication seems to be necessary [13]; therefore, the aim of the current study is to evaluate the CVD risk factors in Iranian patients with metabolic syndrome using FRS.

\section{Methods \\ Subjects}

This study is a part of the "Red Ruby" study, a crosssectional investigation of 160 Iranian adult patients with metabolic syndrome living in Tehran; the details of this study has been reported elsewhere $[15,16]$. Briefly, this was an internet-based lifestyle modification interactive program, and we enrolled community-dwelling individuals from June 22 to August 22, 2012. Target group of the study was the patients with metabolic syndrome according to the National Cholesterol Education Program's Adult Treatment Panel (NCEP-ATP)-III criteria [17] (except for waist circumference which was defined as $\geq 90 \mathrm{~cm}$ for both genders for Iranian population [18]). Participants were aged 20 years and above and have no history of diabetes, cancer, and cardiovascular and/or renal diseases. They also did not have any history of taking medication for hypertension or dyslipidemia. The protocol of the current study has been approved by the ethics committee of Tehran University of Medical Sciences (97/130/1736) and ethics committee of Tabriz University of Medical Sciences (5/92/1228), and written informed consent was obtained from all of the participant's prior participation in the study.

\section{Clinical and laboratory assessments}

Anthropometric assessments and blood pressure measurements were measured by trained nurses as described previously [16]. Biochemical parameters including serum total cholesterol TC, low density lipoprotein cholesterol (LDL-C), high density lipoprotein cholesterol (HDL-C), fasting serum glucose (FSG), and triglyceride (TG) were measured by enzymatic colorimetric method (ParsAzmoon, Tehran-Iran).

\section{Assessment of the cardiovascular risk}

FRS was used to investigate the risk of cardiovascular disease [11]. FRS scores were calculated based on the six coronary risk factors including age, gender, TC, HDL-cholesterol, systolic blood pressure, and smoking habits. The cutoffs for calculating FRS were as follows: TC < 160, 160-199, 200-239, 240-279, and $\geq 280 \mathrm{mg} / \mathrm{dL}$; for systolic blood pressure: <120, 120-129, 130-139, $140-159$, and $\geq 160 \mathrm{mmHg}$; and for HDL-C: $<40,40-49$, $50-59$, and $\geq 60 \mathrm{mg} / \mathrm{dL}$ [11]. Ten-year risk in percentage was calculated by total points ( 1 point $6 \%, 2$ points $8 \%, 3$ points $10 \%, 4$ points $12 \%, 5$ points $16 \%, 6$ points $20 \%, 7$ points $25 \%, 10$ points or more $>30 \%$ ). Absolute CVD risk percentage over 10 years was classified as low risk $(<10 \%)$, intermediate risk (10-20\%), and high risk (>20\%) [11].

\section{Statistical analysis}

Statistical analysis was performed with Statistical Package for Social Science (SPSS 18 for windows, SPSS Inc. headquarter, Chicago, USA). Normality of data was analyzed by Kolmogorov-Smirnov test. Continuous and discrete variables are presented as mean $\pm \mathrm{SD}$ and number and percent, respectively. Analysis of variance (ANOVA) was used to test the difference between biochemical variables between three groups. Multiple logistic regression analysis was used to examine the association between risk factors of metabolic syndrome and 10-year risk for cardiovascular disorders (according to FRS scoring) as independent and dependent variables, respectively. Adjusted odds ratio and 95\% confidence intervals were calculated for FRS different levels. The potential confounding variables in the multiple logistic regression analysis were age and body mass index. $P$ values less than 0.05 were regarded as statistically significant.

The sample size of the patient population was calculated based on the overall prevalence of MS in the Iranian general population [19]. An estimate of that magnitude with 95\% confidence limits and $80 \%$ relative precision required a sample size of 140 . With a $10 \%$ allowance for any dropouts, the calculated sample size was 160 .

\section{Results}

The mean age of participants was $44.02 \pm 10.02$ years old. Overall, $77.5,16.3$, and $6.3 \%$ of patients with metabolic syndrome were at low, intermediate, and high risk of CVD according to FRS categorization. Baseline characteristics of study participants are presented in Table 1. As shown in this table, mean age of participants was $44.02 \pm 10.02$, and $33.8 \%$ of participants were female gender. Figure 1 presents the association between number of metabolic syndrome components and FRS categories among participants. As shown in this figure, the highest prevalence of patients with two or three risk factors of metabolic syndrome were in low and intermediate risk of 
Table 1 Baseline characteristics of patients with metabolic syndrome

\begin{tabular}{ll}
\hline Characteristics & $N=160$ \\
\hline Age (year) & $44.02 \pm 10.02$ \\
Female gender (\%) & $54(33.8 \%)$ \\
SBP $(\mathrm{mmHg})$ & $131.78 \pm 11.03$ \\
DBP $(\mathrm{mmHg})$ & $88.33 \pm 6.45$ \\
WC $(\mathrm{cm})$ & $104.47 \pm 8.76$ \\
FSG $(\mathrm{mg} / \mathrm{dl})$ & $90.09 \pm 13.89$ \\
Serum TG $(\mathrm{mg} / \mathrm{dl})$ & $193.81 \pm 113.02$ \\
Serum TC $(\mathrm{mg} / \mathrm{dl})$ & $195.28 \pm 32.84$ \\
Serum HDL $(\mathrm{mg} / \mathrm{dl})$ & $41.26 \pm 9.97$ \\
\hline
\end{tabular}

$S B P$, systolic blood pressure; $D B P$, diastolic blood pressure; $W C$, waist circumference; $F S G$, fasting serum glucose; $T G$, triglyceride; $T C$, total cholesterol; $H D L$, high density lipoprotein

CVD, while the patients with four or five risk factors of metabolic syndrome were most prevalent in groups with high CVD risk. Prevalence of metabolic syndrome components in different categories of FRS is presented in Table 2. The highest prevalence of all of metabolic syndrome components was in the low-CVD risk according to the FRS grouping $(P<0.05)$, while the lowest prevalence of these components was in the high CVD risk group $(P<0.05)$.

Multiple logistic regression evaluating the association between FRS risk categories and risk factors of metabolic syndrome (Table 3) showed that high blood pressure and fasting serum glucose were potent determinants of intermediate and high risk categories of FRS compared with the low-risk group $(P<0.01, P<0.05$, respectively).

\section{Discussion}

In the present study, there was a significant relationship between FRS risk scores and components of metabolic syndrome including high systolic blood pressure (SBP), diastolic blood pressure (DBP), waist circumference (WC), and FSG. Moreover, according to the results of logistic regression analysis, high SBP and high FSG make patients 3-5 times more susceptible to be in intermediate and high risk of cardiovascular disease. These findings were in accordance of the results of previous studies. In the study by Takahashi et al. [8], CAD risk was associated with higher SBP, TC, and lower HDL concentrations in general population. In their study, having metabolic syndrome presented a fourfold greater probability of high CAD risk score. Other study by Yousefzadeh et al. [13] also found higher prevalence of 10 -year risk of CVD in patients with metabolic syndrome $(P<0.001)$.

Totally, $77.5 \%$ of patients were in low risk of CVD, whereas 16.3 and $6.3 \%$ were in intermediate and high risk of CVD, respectively. These values were comparable with the previous study performed in Kerman, Iran, while the corresponding numbers were $74.3,18.1$, and $7.6 \%$, respectively. Moreover, in our study, the number of metabolic syndrome components in patients of high risk score was significantly higher than the other groups. Therefore, FRS can be used as a diagnostic tool for presence of metabolic syndrome as also confirmed by previous studies $[5,10,13]$. In the study by Takahashi et al. [8], same as our results, a positive correlation was observed between CAD risk score and the number of metabolic syndrome components; the greater the metabolic syndrome components, the higher the risk of developing $\mathrm{CAD}$, although the results of studies in the predictive capacity of FRS in cardiovascular disease risk are inconsistent. Several studies reported that metabolic syndrome is a better predictor of CVD risk compared with FRS because of high dependency of FRS to age, underestimation of cardiovascular disorders in young ages, and lack of coverage several prominent features of metabolic syndrome such as obesity, hyper-triglyceridemia, and elevated high CRP levels $[20,21]$; however, two previous US reports $[22,23]$ showed that FRS is more predictive for CVD risk than metabolic syndrome. More studies in different age groups and geographical locations are needed to address this question.

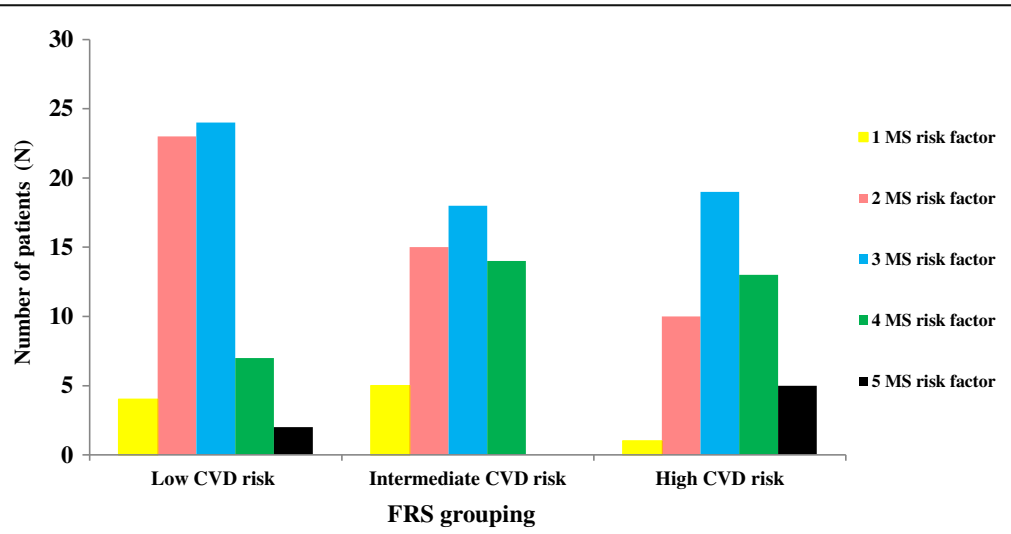

Fig. 1 Association between Framingham risk score risk categories and number of metabolic syndrome components 
Table 2 Prevalence of metabolic syndrome components according to Framingham risk score (FRS)

\begin{tabular}{|c|c|c|c|c|c|}
\hline & $N(\%)$ & $\begin{array}{l}\text { Low risk } \\
N(\%)\end{array}$ & $\begin{array}{l}\text { Intermediate risk } \\
N(\%)\end{array}$ & $\begin{array}{l}\text { High risk } \\
N(\%)\end{array}$ & $P^{*}$ \\
\hline Patients in group & $160(100)$ & $124(77.5)$ & $26(16.3)$ & $10(6.3)$ & - \\
\hline High SBP (mmHg) & $125(78.1)$ & $90(72)$ & $25(20)$ & 10(8) & 0.007 \\
\hline High DBP (mmHg) & $140(87.5)$ & $112(80)$ & $22(15.7)$ & $6(4.3)$ & 0.04 \\
\hline High WC (cm) & $118(73.8)$ & $93(78.8)$ & $19(16.1)$ & $6(5.1)$ & 0.018 \\
\hline High FSG (mg/dl) & $16(10)$ & $7(43.8)$ & $6(37.5)$ & $3(18.8)$ & 0.002 \\
\hline High Serum TG (mg/dl) & $107(66.9)$ & $81(75.7)$ & $17(15.9)$ & $9(8.4)$ & 0.276 \\
\hline Low Serum HDL (mg/dl) & $114(71.3)$ & $87(76.3)$ & $19(16.7)$ & $8(7)$ & 0.582 \\
\hline
\end{tabular}

$S B P$, systolic blood pressure; $D B P$, diastolic blood pressure; $W C$, waist circumference; $F S G$, fasting serum glucose; $T G$, triglyceride; $H D L$, high density lipoprotein concentrations. Italic digits provide significant values

${ }^{*}$ Chi-square test was used for comparisons

Although the FRS is a useful tool for predicting the risk of CVD, however, it has also several limitations that should be considered before applying its results to population: first of all, the FRS is an estimation algorithm and cannot be used as a medical examination; secondly, because of the under-representation of young population in the original cohort, the FRS may be an imprecise tool in this population; and thirdly, the FRS did not include several other potential CVD risk factors like family history of CVD or diabetes [24, 25]. Moreover, the cross-sectional nature of the current study makes it difficult to better address the direction of causation between variables.

\section{Conclusion}

The current study, for the first time, evaluated the predictive value of FRS for estimation of 10-year CVD risk in patients with metabolic syndrome in Iran. Due to relatively high prevalence of metabolic syndrome in Iranian population, the results will be useful for designing interventional strategies to prevent CVD in these patients. In the current study, a potent relationship between FRS risk scores and components of metabolic syndrome has been identified. High SBP and FSG were associated with meaningfully increased risk of CVD compared with other parameters. More studies are needed to further clarify these associations in a longitudinal design.

Table 3 Association between risk factors of metabolic syndrome and 10-year risk for cardiovascular disorders (according to Framingham risk score (FRS) scoring)

\begin{tabular}{|c|c|c|c|c|}
\hline \multirow[t]{2}{*}{ Parameter } & & \multicolumn{3}{|l|}{ FRS } \\
\hline & & Low $(<10 \%)$ & Intermediate (10-20\%) & High (> 20\%) \\
\hline \multirow[t]{2}{*}{ Age (year) } & OR & Ref. & 1.30 & 1.82 \\
\hline & $95 \% \mathrm{Cl}$ & 1 & $1.17-1.45$ & $1.38-2.39$ \\
\hline \multirow[t]{2}{*}{ Female gender } & OR & Ref. & 0.057 & 0.068 \\
\hline & $95 \% \mathrm{Cl}$ & 1 & $0.014-0.242$ & $0.017-0.089$ \\
\hline \multirow[t]{2}{*}{ High SBP (mmHg) } & OR & Ref. & 4.98 & 5.70 \\
\hline & $95 \% \mathrm{Cl}$ & 1 & $2.3-59.12$ & $3.12-10.15$ \\
\hline \multirow[t]{2}{*}{ High DBP $(\mathrm{mmHg})$} & OR & Ref. & 0.25 & 0.18 \\
\hline & $95 \% \mathrm{Cl}$ & 1 & $0.04-1.77$ & $0.009-3.66$ \\
\hline \multirow[t]{2}{*}{ High WC (cm) } & OR & Ref. & 1.67 & 3.55 \\
\hline & $95 \% \mathrm{Cl}$ & 1 & $0.4-6.36$ & $0.27-45.76$ \\
\hline \multirow[t]{2}{*}{ High FSG (mg/dl) } & OR & Ref. & 3.7 & $4.07-71.55$ \\
\hline & $95 \% \mathrm{Cl}$ & 1 & $1.16-7.45$ & $1.25-47.14$ \\
\hline \multirow[t]{2}{*}{ High TG (mg/dl) } & OR & Ref. & 2.06 & $0.58-7.28$ \\
\hline & $95 \% \mathrm{Cl}$ & 1 & 14.35 & $1.75-19.13$ \\
\hline \multirow[t]{2}{*}{ Low HDL (mg/dl) } & OR & Ref. & 0.59 & $0.17-2.00$ \\
\hline & $95 \% \mathrm{Cl}$ & 1 & 0.25 & $0.019-3.4$ \\
\hline
\end{tabular}

Ref, reference group; $S B P$, systolic blood pressure; $D B P$, diastolic blood pressure; $W C$, waist circumference; FSG, fasting serum glucose; $T G$, triglyceride; $H D L$, high density lipoprotein concentrations. Italic digits provide significant values 


\section{Abbreviations}

ANOVA: Analysis of variance; CAD: Coronary artery disease; CRP: C-reactive protein; CVD: Cardiovascular disease; DBP: Diastolic blood pressure; FRS: Framingham risk score; FSG: Fasting serum glucose; HDL: High density lipoprotein; LDL: Low density lipoprotein; NCEP-ATP: National Cholesterol Education Adult Treatment Panel; SBP: Systolic blood pressure; TC: Total cholesterol; TG: Triglyceride; WC: Waist circumference

\section{Acknowledgements}

The authors appreciate the cooperation of the patients in the current study.

\section{Funding}

This research received no specific grant from any funding agency in the public, commercial, or not-for-profit sectors.

\section{Availability of data and materials}

The data and the study's material are available for all from the scientists with reasonable request.

\section{Authors' contribution}

MAF was involved in designing the project, wrote and revised the article draft, and analyzed the data. $L J$ was also involved in designing the project and gathered the data. FR was involved in Framingham risk score modeling. All authors read and approved the final manuscript.

\section{Competing interest}

The authors declare that they have no competing interests.

\section{Ethics approval and consent to participate}

The protocol of the current study has been approved by the ethics committee of Tehran University of Medical Sciences (97/130/1736) and Ethics committee of Tabriz University of Medical Sciences (5/92/1228), and written informed consent was obtained from all of the participant's prior participation in the study.

\section{Consent for publication}

All of the authors have read and approved the article draft and were in agreement of article submission.

\section{Publisher's Note}

Springer Nature remains neutral with regard to jurisdictional claims in published maps and institutional affiliations.

\begin{abstract}
Author details
${ }^{1}$ Tabriz Health Services Management Research Center, Health Education and Health Promotion Department, Tabriz University of Medical Sciences, Tabriz, Iran. ${ }^{2}$ Drug Applied Research Center, Department of Community Nutrition, Faculty of Nutrition, Tabriz University of Medical Sciences, Tabriz, Iran. ${ }^{3}$ Department of Social Medicine, School of Medicine, Jahrom University of Medical Sciences, Jahrom, Iran.
\end{abstract}

Received: 9 May 2017 Accepted: 3 November 2017

Published online: 13 November 2017

\section{References}

1. Grundy SM, Brewer HB, Cleeman JI, Smith SC, Lenfant C. Definition of metabolic syndrome: report of the National Heart, Lung, and Blood Institute/American Heart Association conference on scientific issues related to definition. Circulation. 2004:109(3):433-8.

2. Malik S, Wong ND, Franklin SS, Kamath TV, Gilbert JL, Pio JR, Williams GR. Impact of the metabolic syndrome on mortality from coronary heart disease, cardiovascular disease, and all causes in United States adults. Circulation. 2004;110(10):1245-50.

3. Khaki Khatibi F, Yaghoubi A, Zarghami N, Rahbani M, Babaie H. Evaluation of hs-CRP, antioxidant markers and MDA in patients of coronary artery disease (CAD) containing non-smokers and non-diabetics. J Cardiovasc Thorac Res. 2011;2(4):13-8

4. Pezeshkian M, Darbin A, Rashidi MR, Vatankhah A, Golmohammadi Z, Afrasiabi A, et al. The effect of atherogenic diet with or without enzyme inhibitors on the incidence and progress of atherosclerosis in rabbits. J Cardiovasc Thorac Res. 2011;3(1):7-10.
5. Mottillo S, Filion KB, Genest J, Joseph L, Pilote L, Poirier P, et al. The metabolic syndrome and cardiovascular risk: a systematic review and meta-analysis. J Am Coll Cardiol. 2010;56(14):1113-32.

6. Sokhanvar S, Mazaki RRS, Mousavinasab N, Golmohammadi Z. The association between serum lipoprotein (a) and other cardiac risk factors with the severity of coronary artery disease. J Cardiovasc Thorac Res. 2011;3(1):35-9.

7. Sharifi MH, Eftekhari MH, Ostovan MA, Rezaianazadeh A. Effects of a therapeutic lifestyle change diet and supplementation with Q10 plus L-carnitine on quality of life in patients with myocardial infarction: a randomized clinical trial. J Cardiovasc Thorac Res. 2017;9(1):21-8.

8. Takahashi MM, de Oliveira EP, de Carvalho ALR, de Souza Dantas LA, Burini FHP, Portero-McLellan KC, Burini RC. Metabolic syndrome and dietary components are associated with coronary artery disease risk score in free-living adults: a cross-sectional study. Diabetol Metab Synd. 2011;3(1):1-7

9. Mirinazhad MM, Farhangi MM, Jahangiri L, Yaghoubi A. Serum adiponectin concentrations in relation to lipid profile, anthropometric variables and insulin resistance in patients with metabolic syndrome. Mal J Nutr. 2014 20(3):283-0

10. Wannamethee SG, Shaper AG, Lennon L, Morris RW. Metabolic syndrome vs Framingham Risk Score for prediction of coronary heart disease, stroke, and type 2 diabetes mellitus. Archives Intern Med. 2005;165(22):2644-50.

11. Sohn C, Kim J, Bae W. The framingham risk score, diet, and inflammatory markers in Korean men with metabolic syndrome. Nutr Res Pract. 2012; 6(3):246-53.

12. Wilson PWF, D'Agostino RB, Levy D, Belanger AM, Silbershatz $H$, Kannel WB. Prediction of coronary heart disease using risk factor categories. Circulation. 1998;97(18):1837-47

13. Yousefzadeh G, Shokoohi M, Najafipour H, Shadkamfarokhi M. Applying the Framingham risk score for prediction of metabolic syndrome: The Kerman Coronary Artery Disease Risk Study, Iran. ARYA atherosclerosis. 2015;11(3):179-85.

14. Farhangi MM, Jahangiry L, Mirinazhad MM, Shojaeezade D, Montazeri A Yaghoubi A. A web-based interactive lifestyle modification program improves lipid profile and serum adiponectin concentrations in patients with metabolic syndrome: the "Red Ruby" study. Int J Diab Develop Ctrs. 2017;37(1): 21-30.

15. Jahangiri L, Shojaeezadeh D, Najafi M, Mohammad K, Abbasalizad Farhangi M, Montazeri A. "Red Ruby": an interactive web-based intervention for life style modification on metabolic syndrome: a study protocol for a randomized controlled trial. BMC-Public Health. 2014;14(1):748-56.

16. Jahangiry L, Shojaeizadeh D, Farhangi MA, Yaseri M, Mohammad K, Najafi M Montazeri A. Interactive web-based lifestyle intervention and metabolic syndrome: findings from the Red Ruby (a randomized controlled trial). Trials. 2015;16(1):418-28

17. Grundy SM, Hansen B, Smith SC, Cleeman J, Richard A. Clinical management of metabolic syndrome: report of the American Heart Association/National Heart, Lung, and Blood Institute/American Diabetes Association conference on scientific issues related to management. Circulation. 2004;109:551-6.

18. Esteghamati A, Abbasi M, Rashidi A, Meysamie A, Khalilzadeh O, Haghazali M. Optimal waist circumference cut-offs for the diagnosis of metabolic syndrome in adults: results from the third national survey of risk factors of non-communibale disease (SuRFNCD). Diab Med. 2009;26:745-6.

19. Noshad S, Abbasi M, Etemad K, Meysamie A, Afarideh M, Khajeh E, Asgari F, Mousavizadeh M, Rafei A, Neishaboury M, Ghajar A, Nakhjavani M, Koohpayehzadeh J, Esteghamati A. Prevalence of metabolic syndrome in Iran: a 2011 update. J Diabetes. 2017:9(5):518-25.

20. Tzoulaki I, Liberopoulos G, loannidis JPA. Assessment of claims of improved prediction beyond the Framingham risk score. JAMA. 2009; 302(21):2345-52.

21. Gode S, Aksu T, Demirel A, Sunbul M, Gul M, Bakır I, et al. Effect of vitamin D deficiency on the development of postoperative atrial fibrillation in coronary artery bypass patients. J Cardiovasc Thorac Res. 2016;8(4):140-6.

22. Stern MP, Williams K, González-Villalpando C, Hunt KJ, Haffner SM. Does the metabolic syndrome improve identification of individuals at risk of type 2 diabetes and/or cardiovascular disease? Diabetes Care. 2004;27(11):2676-81.

23. McNeill AM, Rosamond WD, Girman CJ, Golden SH, Schmidt MI, East HE, Ballantyne CM, Heiss G. The metabolic syndrome and 11-year risk of incident cardiovascular disease in the atherosclerosis risk in communities study. Diabetes Care. 2005;28(2):385-90. 
24. Hemann BA, Bimson WF, Taylor AJ. The Framingham Risk Score: an appraisal of its benefits and limitations. Am Heart Hosp J. 2007;5:91-6.

25. Aliasgharzadeh A, Khalili M, Mirtaheri E, Gargari BP, Tavakoli F, Farhangi MA, Babaei H,Dehghan P. A Combination of Prebiotic Inulin and Oligofructose Improve Some of Cardiovascular Disease Risk Factors in Women with Type 2 Diabetes: A Randomized Controlled Clinical Trial. Advanced Pharmaceutical Bulletin 5 2015;(4):507-14.

Submit your next manuscript to BioMed Central and we will help you at every step:

- We accept pre-submission inquiries

- Our selector tool helps you to find the most relevant journal

- We provide round the clock customer support

- Convenient online submission

- Thorough peer review

- Inclusion in PubMed and all major indexing services

- Maximum visibility for your research

Submit your manuscript at www.biomedcentral.com/submit
Biomed Central 